\title{
Spatial and temporal analysis of the mid-summer dry spells for the summer rainfall region of South Africa
}

\author{
MG Mengistu' ${ }^{1,2}$, C Olivier $^{1}$, JO Botai ${ }^{1,2,3}$, AM Adeola $^{1,3,4}$ and S Daniel ${ }^{1,2}$ \\ 'South African Weather Service, Private Bag X097, Centurion, South Africa \\ ${ }^{2} S c h o o l$ of Agricultural, Earth and Environmental Sciences, University of KwaZulu-Natal, Pietermaritzburg, South Africa \\ ${ }^{3}$ Department of Geography, Geoinformatics and Meteorology, University of Pretoria, Pretoria, South Africa \\ ${ }^{4}$ UP Institute for Sustainable Malaria Control, School for Health Systems and Public Health, University of Pretoria, Pretoria, South Africa
}

\begin{abstract}
South Africa is frequently subjected to severe droughts and dry spells during the rainy season. As such, rainfall is one of the most significant factors limiting dryland crop production in South Africa. The mid-summer period is particularly important for agriculture since a lack of rain during this period negatively affects crop yields. Dry spell frequency analyses are used to investigate the impacts of sub-seasonal rainfall variability on crop yield, since seasonal rainfall totals alone do not explain the relationship between rainfall and crop yields. This study investigated the spatial and temporal occurrences of the mid-summer dry spells based on magnitude, length and time of occurrence in the major maize growing areas of the summer rainfall region of South Africa. Three thresholds of $5 \mathrm{~mm}, 10 \mathrm{~mm}$, and $15 \mathrm{~mm}$ total rainfall for a pentad were used for the analysis of dry spells. Dry spell analysis showed that dry pentads occur during mid-summer with differing intensity, duration and frequency across the summer rainfall region. Annual frequency of dry pentads for the mid-summer period ranged between 0 and 4 pentads for the $5 \mathrm{~mm}$ threshold and 1 to 7 for the $10 \mathrm{~mm}$ and $15 \mathrm{~mm}$ thresholds. The non-parametric Mann-Kendall trend analysis of the dry pentads indicates that there is no significant trend in the frequency of dry spells at a $95 \%$ confidence level. The initial and conditional probabilities of getting a dry spell using the Markov chain model also showed that there is a $32 \%$ to $80 \%$ probability that a single pentad will be dry using the $15 \mathrm{~mm}$ threshold. There is a $5 \%$ to $48 \%$ probability of experiencing two consecutive dry pentads and $1 \%$ to $29 \%$ probability of getting three consecutive dry pentads. The duration and intensity of dry spells, as well as the Markov chain probabilities, showed a decrease in dry spells from west to east of the maize-growing areas of the summer rainfall region of South Africa.
\end{abstract}

\section{INTRODUCTION}

South Africa is a semi-arid country with mean annual rainfall totals below $500 \mathrm{~mm}$ (Taljaard, 1996). In most parts of South Africa rainfall occurs during the austral summer months from October to March (Harrison 1984; Hart et al., 2010). The most significant increase in rainfall over the summer rainfall region starts in September along the southeast and east coast, then the increase in rainfall spreads to the eastern interior parts in October extending to the western interior from October to November (Taljaard, 1986). In December a break in the rising rainfall occurs over part of the summer rainfall region (Taljaard, 1986). The other distinct rainfall regions over South Africa occur along the southern coast of the country where rainfall occurs all year round (Engelbrecht et al., 2014), as well as the south-western region which receives the majority of its rain during the winter months (Reason et al., 2002).

Southern Africa summer rainfall experiences significant rainfall variability, with recurrent wet and dry spells and severe droughts (Richard et al., 2001). Drought is a natural phenomenon that occurs when there is a temporal imbalance of water availability due to a persistent lower than average precipitation over a certain period of time (Pereira et al., 2009). Several studies in the past have focused on the occurrence, intensity, impact and prediction of drought on an annual and seasonal basis. However, dry spells are equally important to the agricultural sector, as the timing of the occurrence and intensity of the dry period is more important than seasonal shortfalls in rainfall. Usman and Reason (2004) highlighted that a season with above-average rainfall may not be better than a below-average season over an agricultural region if the rainfall during the season is not well distributed in space and time. Crops are more likely to do well with evenly distributed rains than intermittent heavy showers interrupted by prolonged dry periods (Usman and Reason, 2004). Various crops, such as maize, are vulnerable to dry spells during specific phenological stages (Tadross et al., 2009; Mupangwa et al., 2011). Water stress is one of the major limiting factors in dryland (rainfed) agriculture and its effects include stunted growth, delayed maturity and low crop productivity (Mzezewa et al., 2010). The flowering stage of maize has been found to be the most sensitive stage to water stress, for example, leading to reductions in crop growth, biomass production and finally yield (Du Plessis, 2003; Masupha et al., 2016). Therefore, planting dates should be chosen to ensure that this stage coincides with normally favourable growing conditions and does not coincide with midsummer drought periods (Du Plessis, 2003).

Rainfall has been identified as the most pressing and significant factor limiting dryland crop production in South Africa. The mid-summer period is particularly important since a lack of rain

\section{CORRESPONDENCE}

MG Mengistu

\section{EMAIL}

Michael.Mengistu@weathersa.co.za mgmengistu@gmail.com

\section{DATES}

Received: 11 October 2019

Accepted: 15 December 2020

\section{KEYWORDS}

pentad rainfall

mid-summer

dry spells

Markov chain model

South Africa

\section{COPYRIGHT}

() The Author(s)

Published under a Creative Commons Attribution 4.0 International Licence (CC BY 4.0) 
for even a few days during this period may decrease crop yields. Variability in seasonal rainfall totals alone may not explain the relationship between rainfall and crop yields, hence dry spell frequency analyses are used globally to investigate the implications of sub-seasonal rainfall variability on food security (Usman and Reason 2004). Dry spells are defined as extended periods with no rainfall within a rainy season (Ngetich et al., 2014). Studies in semi-arid environments in Sub-Saharan Africa have indicated that dry spells range between 5 and 15 days (Usman and Reason 2004). It has been observed that in the summer rainfall region of Southern Africa, there is a break in rainfall during mid-summer when the cyclonic (baroclinic) regime in early summer switches to a dominantly tropical (barotropic) system, characteristic of late summer (Bhalotra, 1984). With the exception of a study by Grobler (1993), little research has been devoted to dry spell characteristics in South Africa.

The rainfall time-series is characterised by periods of wetness (wet spells) and dryness (dry spells). Therefore, a threshold for defining wet and dry days is required when analysing spells of rainfall, since the frequency distribution of the length of the spells is dependent on the selected threshold (Bärring et al., 2006). Different thresholds have been used internationally based on the aspect of the spells that needed to be considered. Moon et al. (1994) and Matrin-Vide and Gomez (1999) have used $0.1 \mathrm{~mm}$ per day, Frei et al. (2003), Douguedroit (1987), and Usman and Reason (2004) have used a threshold of $1.0 \mathrm{~mm}$ daily precipitation, Perzyna (1994) used a threshold of $2.0 \mathrm{~mm}$ per day, and Ceballos et al. (2004) have used a threshold of $10 \mathrm{~mm}$ daily rainfall for wet and dry spell analysis. Reddy (1990) used a threshold of $3 \mathrm{~mm}$ per day, which is the minimum rainfall depth threshold value for crops to satisfy their crop water requirement during a growing season.

In this study, a dry spell is defined as a period of 5 days (a pentad) during which rainfall totals are less than predefined thresholds. Three thresholds of $5 \mathrm{~mm}, 10 \mathrm{~mm}$, and $15 \mathrm{~mm}$ total rainfall for a pentad were used for the analysis of dry spells. This study aims to perform a detailed spatial and temporal analysis on the occurrence of the mid-summer dry spells (MSD) based on magnitude, length and time of occurrence in the summer rainfall region of South Africa.

\section{DATA AND METHODOLOGY}

Daily rainfall data from the South African Weather Service (SAWS) data bank were used to investigate mid-summer dry spells. Rainfall was measured at either individual rainfall stations or automatic weather stations (AWSs). As mentioned in Kruger and Nxumalo (2017), measurements at manual stations were done at 08:00 SAST and represent the accumulated rainfall over the preceded 24 hours, while AWS data represent the total rainfall accumulated over the period from 08:00 SAST the previous day to 08:00 SAST the current day. Only stations that were operational throughout the study period were selected, with at least $90 \%$ of daily values available. In cases where zero rainfall was recorded for relatively long periods (a month or longer) when surrounding stations recorded significant rainfall amounts, the data were flagged and removed (Kruger and Nxumalo, 2017).

The summer period is defined as the 6-month period extending from October to March. A map illustrating the South African average rainfall totals over the period of October to March is depicted in Fig. 1. Climatological rainfall totals from October to March were calculated and related, as a percentage, to the annual rainfall totals (defined here as June to May to capture the full October to March period). The study area receives $80 \%$ or more of its total annual rainfall from October to March as shown in Fig. 1. Parts of the eastern coastal areas still receive significant rainfall during these months; however, they also receive rainfall during winter and spring, lowering the overall percentage for October to March (NCAR, 2018). From the summer rainfall region, which receives rain mostly during October to March (Fig. 1), only 16

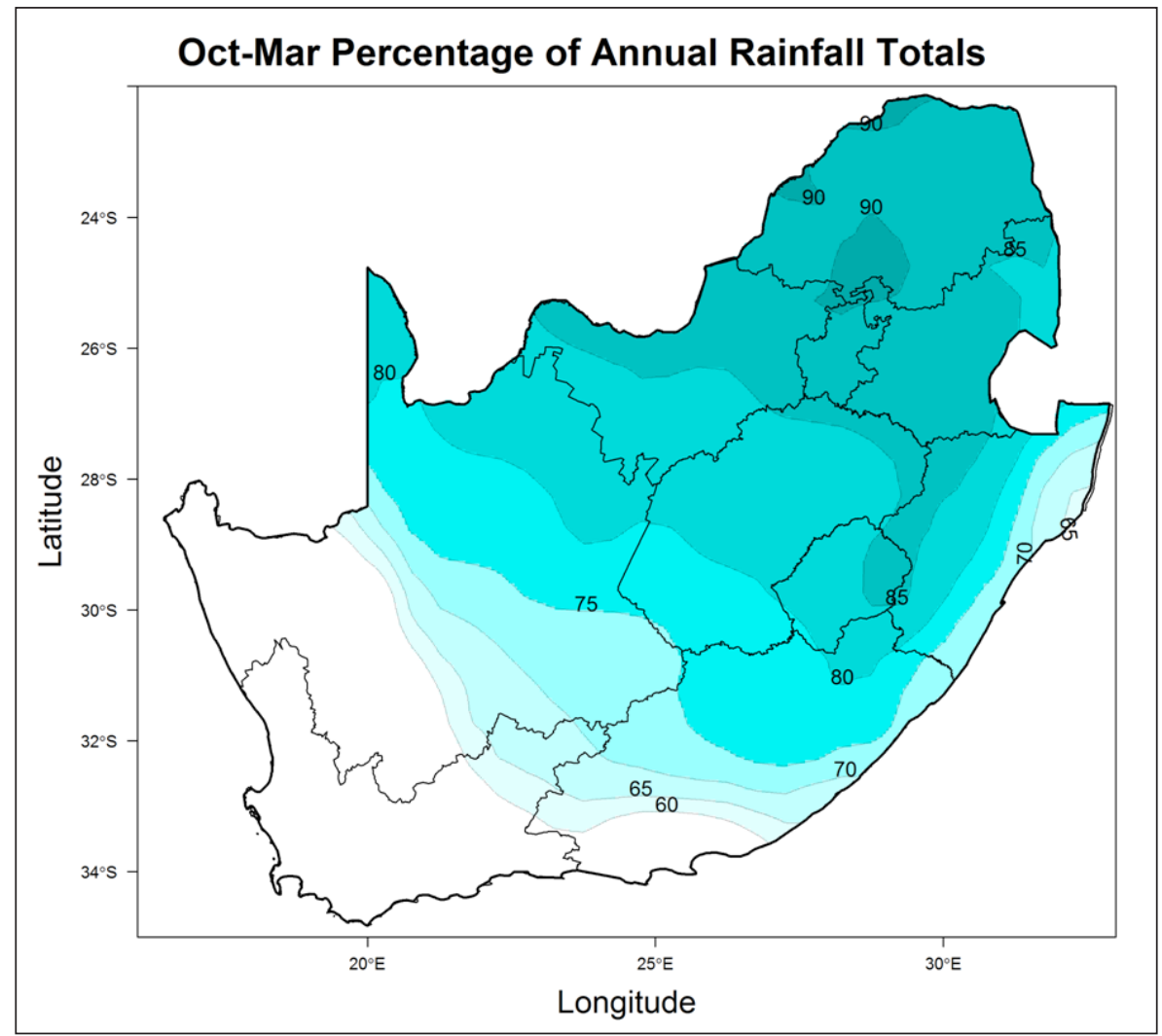

Figure 1. October to March rainfall totals compared with annual rainfall totals (1979-2018) using CPC unified gauge-based analysis of global daily precipitation 


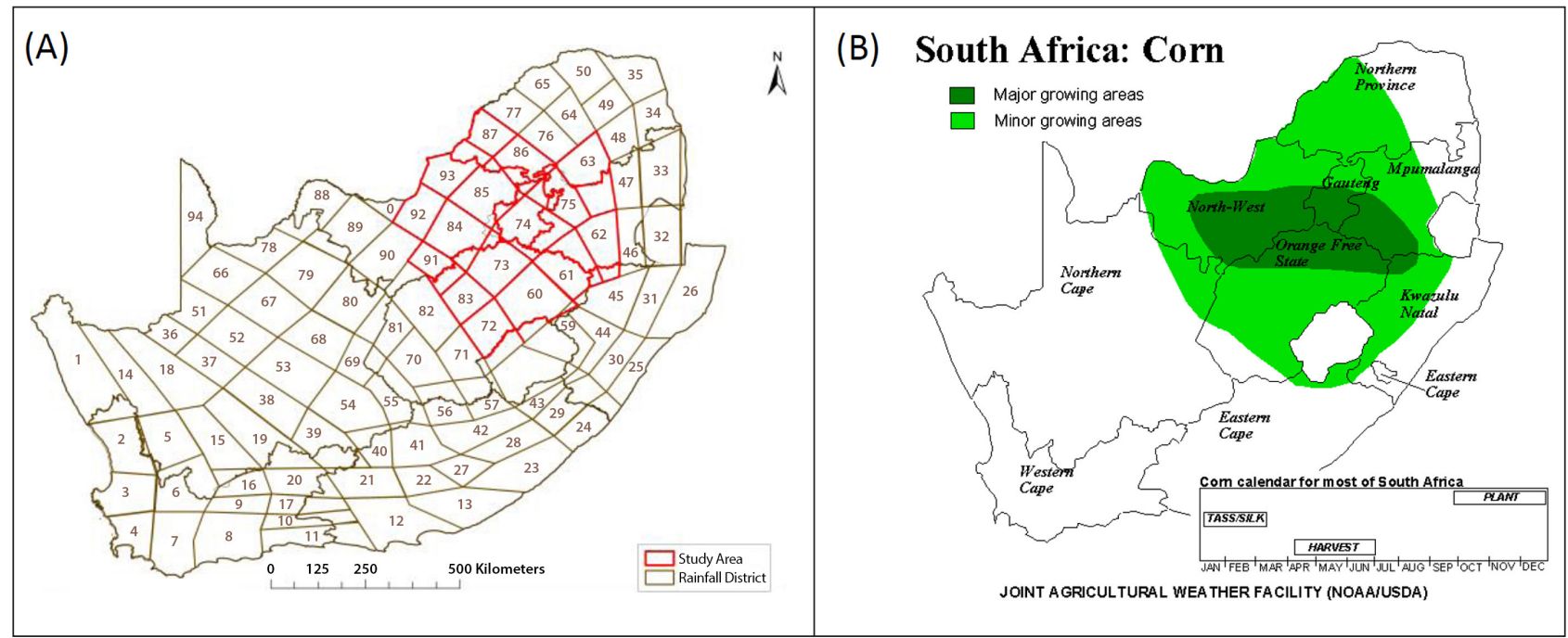

Figure 2. (A) Rainfall districts for South Africa with provincial borders (SAWB, 1972), showing the 16 selected districts with red polygons, (B) A map showing maize-growing areas (AgWeb, 2015)

districts (Fig. 2A) with homogeneous rainfall and seasonality (Kruger, 2011) from the maize-growing areas (Fig. 2.B) were used for further analysis. From the daily district rainfall (Kruger and Nxumalo, 2017), pentad summations (totals) were calculated following the methodology used in Grobler (1993). Pentads were calculated using Julian days; for example, Pentad 1 refers to January 1-5 and Pentad 73 refers to December 27-31. The extra leap year day, 29 February, was added to the $10^{\text {th }}$ pentad. Eight pentads between 12 December (start of Pentad 70) and 20 January (end of Pentad 4) were selected for detailed analysis of the midsummer rainfall for the study area.

Dry and wet spell analysis has been carried out using the Markov chain probability model for the threshold value of $3 \mathrm{~mm}$ rainfall depth per day (15 $\mathrm{mm}$ per pentad). A pentad with less than $15 \mathrm{~mm}$ rainfall was considered as a dry pentad and a pentad with $15 \mathrm{~mm}$ or more rainfall as a wet pentad. The Markov chain model calculates the initial probabilities of getting a dry spell or wet spell for a given pentad. The calculation of conditional probabilities provides the information on the dry spell followed by dry or wet spell and vice-versa. The calculations of initial and conditional probabilities are given below.

Initial probability:

$$
\begin{aligned}
& P_{\mathrm{D}}=F_{\mathrm{D}} / N \\
& P_{\mathrm{W}}=F_{\mathrm{W}} / N
\end{aligned}
$$

Conditional probabilities:

$$
\begin{aligned}
& P_{\mathrm{DD}}=F_{\mathrm{DD}} / F_{\mathrm{D}} \\
& P_{\mathrm{wW}}=F_{\mathrm{WW}} / F_{\mathrm{W}} \\
& P_{\mathrm{DW}}=1-P_{\mathrm{wW}}
\end{aligned}
$$

Consecutive dry and wet pentad probabilities

$$
\begin{aligned}
& 2 \mathrm{D}=P_{\mathrm{Dp} 1} P_{\mathrm{DD} 2} \\
& 2 \mathrm{~W}=P_{\mathrm{Wp} 1} P_{\mathrm{WWp} 2} \\
& 3 \mathrm{D}=P_{\mathrm{Dp} 1} P_{\mathrm{DDp} 2} P_{\mathrm{DDp} 3} \\
& 3 \mathrm{~W}=P_{\mathrm{Wp} 1} P_{\mathrm{Ww} 2} P_{\mathrm{wWp} 3}
\end{aligned}
$$

where, $P_{\mathrm{D}}$ is the probability of the pentad being dry, $P_{\mathrm{W}}$ is the probability of the pentad being wet, $N$ is the number of years of data, $F_{\mathrm{D}}$ is the number of dry pentads, $F_{\mathrm{W}}$ is the number of wet pentads, $P_{\mathrm{DD}}$ is the probability of a dry pentad preceded by a dry pentad, $P_{\mathrm{wW}}$ is the probability of a wet pentad preceded by a wet pentad, $P_{\mathrm{DW}}$ is the probability of a dry pentad preceded by a wet pentad, $F_{\mathrm{DD}}$ is the number of dry pentads preceded by another dry pentad, $F_{\mathrm{Ww}}$ is the number of wet pentads preceded by another wet pentad, $2 \mathrm{D}$ is the probability of 2 consecutive dry pentads starting with a particular pentad, $2 \mathrm{~W}$ is the probability of 2 consecutive wet pentads starting with the pentad, 3D is the probability of 3 consecutive dry pentads starting with the pentad, $3 \mathrm{~W}$ is the probability of 3 consecutive wet pentads starting with the pentad, $P_{\mathrm{Dp} 1}$ is the probability of the pentad being dry (first pentad), $P_{\mathrm{DDp} 2}$ is the probability of the second pentad being dry, given the preceding pentad dry, $P_{\mathrm{DDp} 3}$ is the probability of the third pentad being dry, given the preceding pentad dry, $P_{\mathrm{Wp} 1}$ is the probability of the pentad being wet (first pentad), $P_{\mathrm{wWw}_{2}}$ is the probability of the second pentad being wet, given the preceding pentad wet, and $P_{\text {wwp } 3}$ is the probability of the third pentad being wet, given the preceding pentad wet.

\section{RESULTS AND DISCUSSION}

\section{Time-series analysis of mid-summer rainfall}

Long-term mean monthly rainfall totals were plotted to check the seasonality and rainfall variability for all selected districts from the summer rainfall region. The district rainfall plots exhibited austral summer rainfall seasonality with mean monthly rainfalls peaking in December. Examples of the plots are presented in Fig. 3, showing rainfall seasonality for 4 districts covering different maize-growing regions of the summer rainfall areas of South Africa.

Most studies of mid-summer drought evaluate an already existing climatological dry period within a typical summer season (Bhalotra, 1984; Karnauskas et al., 2013; Perdigón-Morales et al., 2017). During this relatively dry period, precipitation is reduced by up to $40 \%$ and constitutes a clear signal of bimodal nature of the summer precipitation (Perdigón-Morales et al., 2017). However, this does not seem to be the case for the summer rainfall region of central South Africa.

Pentad rainfall distributions for the 16 district rainfall regions contained within the study area are presented in Fig. 4. Pentad rainfall distributions are clearly skewed towards the higher rainfall totals. This is a common feature with sub-monthly rainfall totals (e.g. days and weeks, or in this case pentads). Rainfall totals for months and seasons tend to be less skewed compared to submonthly rainfall totals. This justifies the reason for defining dry periods with thresholds for the dry spell analysis. 


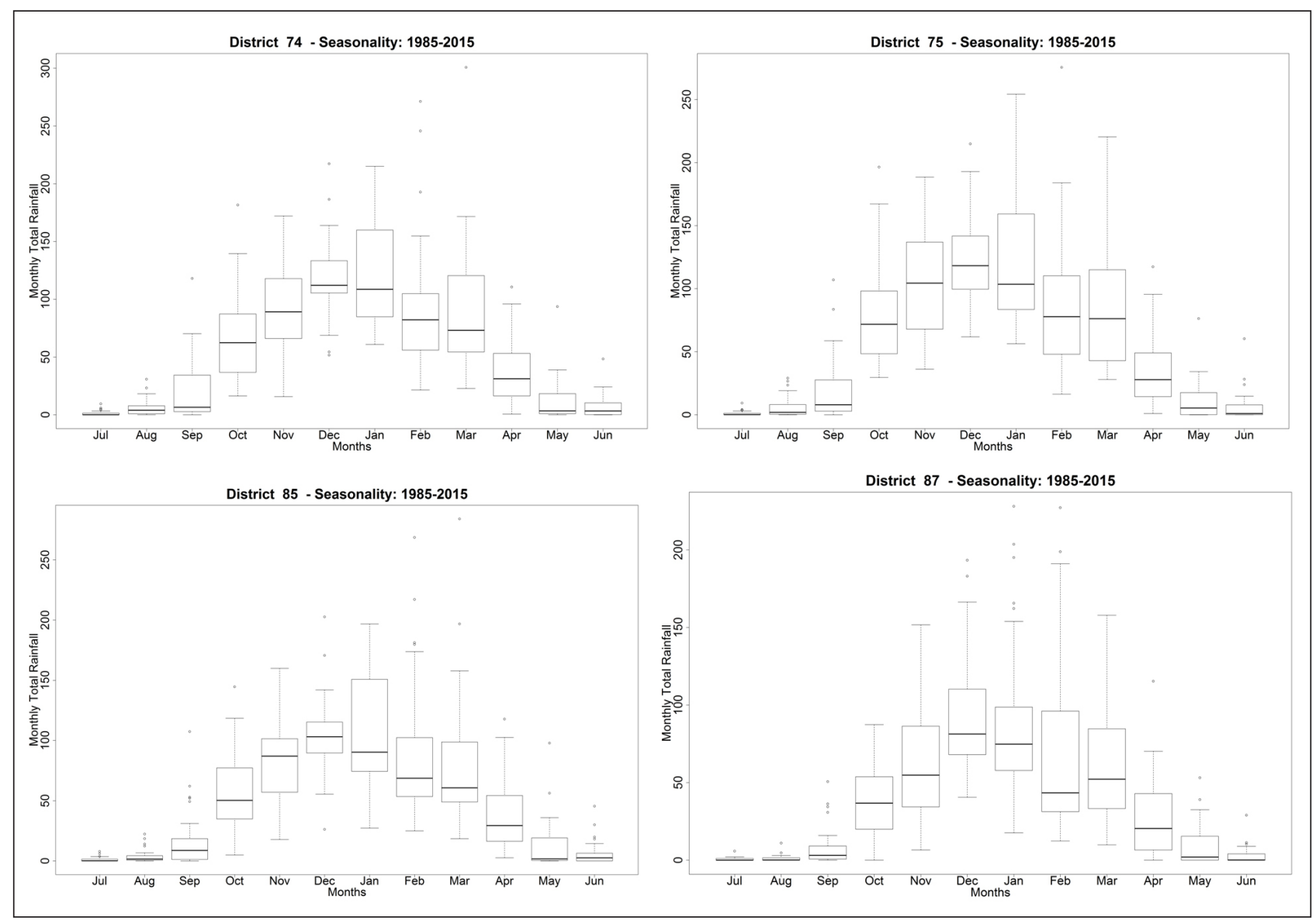

Figure 3. Rainfall seasonality for four different maize-growing regions of South Africa. The black line is the median, box covers the $1^{\text {st }}$ and $3^{\text {rd }}$ quantile $\left(25^{\text {th }}\right.$ and $75^{\text {th }}$ percentiles), whiskers are 1.5 times the interquartile range and dots are outliers outside this range

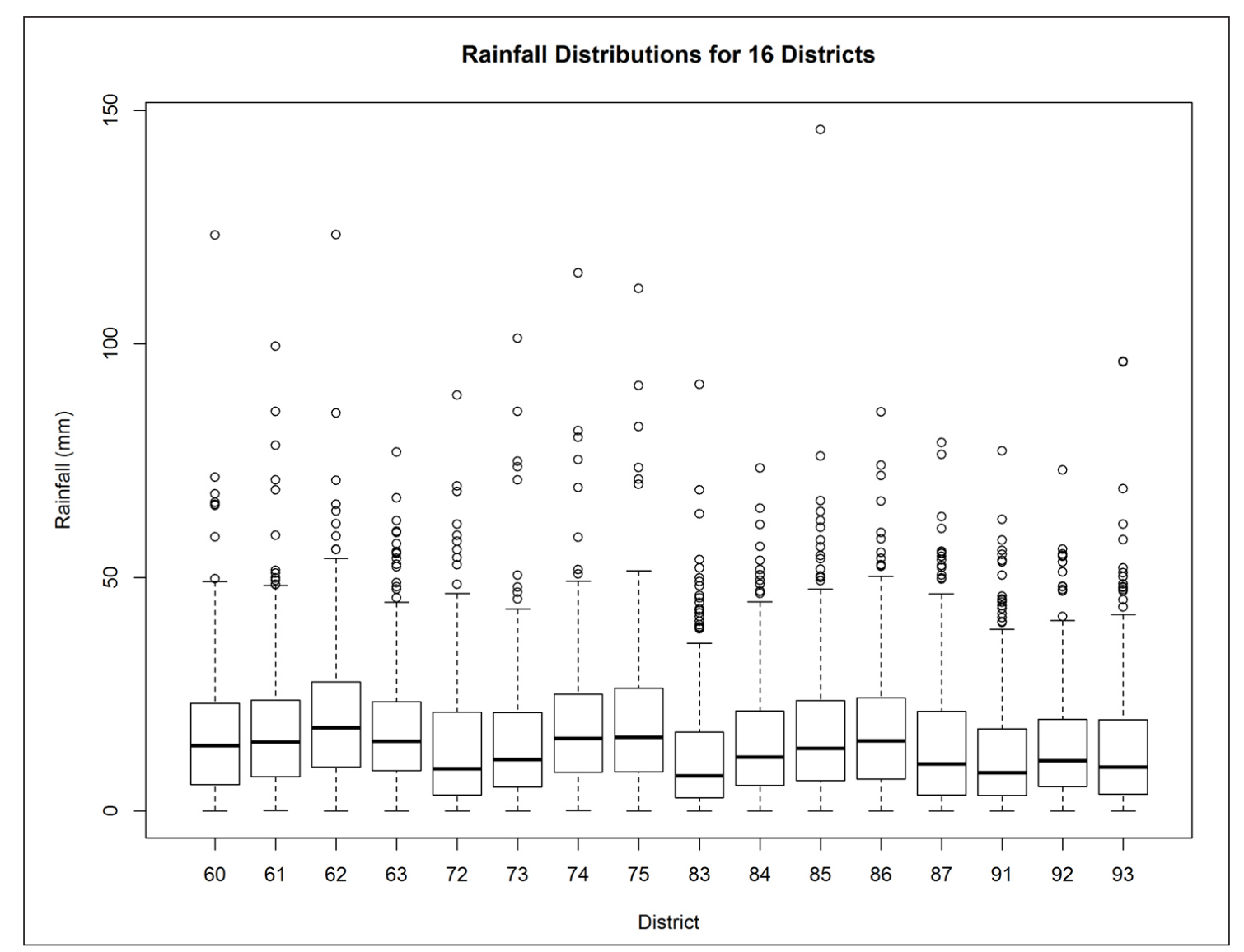

Figure 4. Pentad rainfall distributions for the 16 district rainfall regions contained within the revised study area. The black line is the median, box covers the $1^{\text {st }}$ and $3^{\text {rd }}$ quantile ( $25^{\text {th }}$ and $75^{\text {th }}$ percentiles), whiskers are 1.5 times the interquartile range and dots are outliers outside this range 

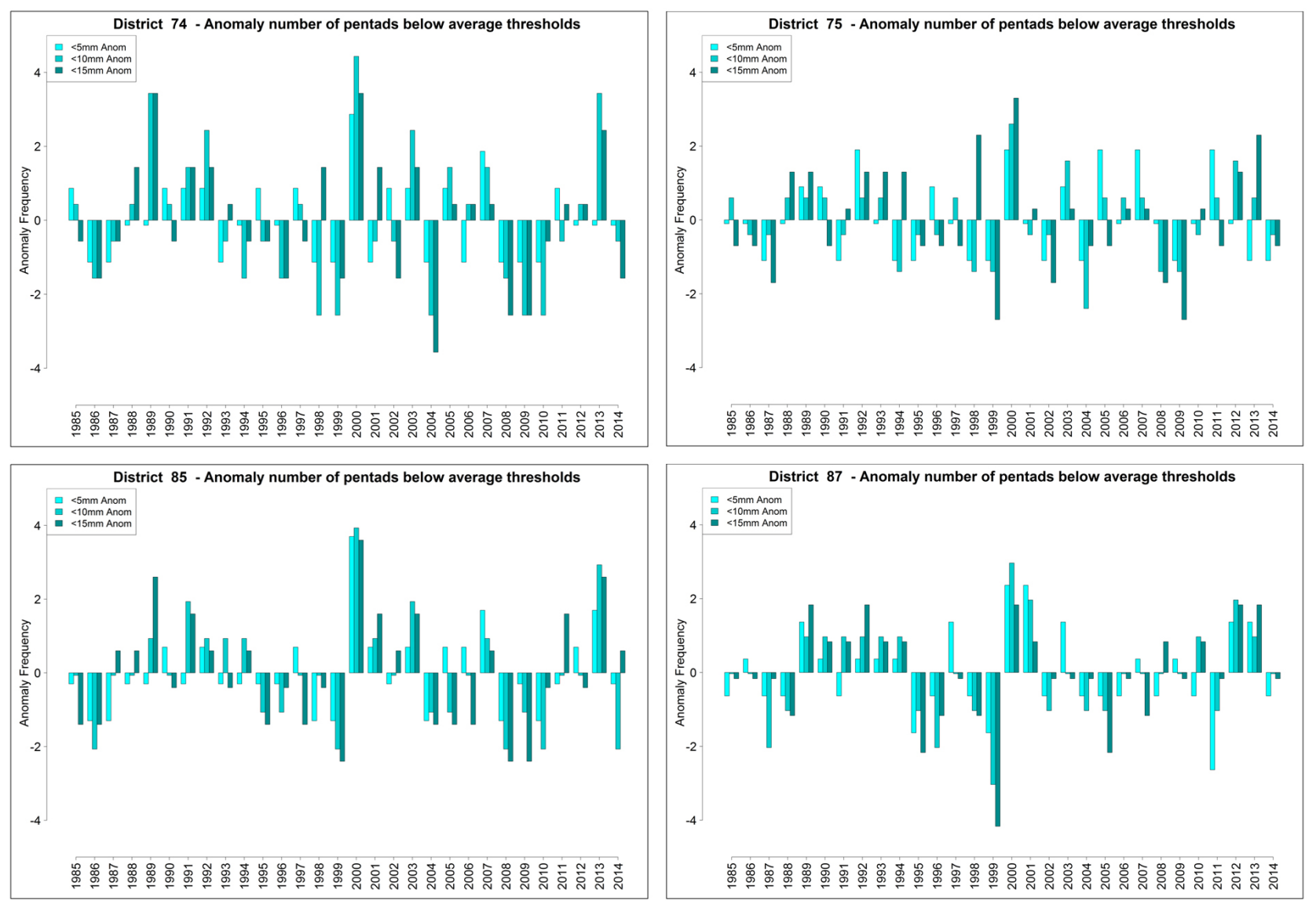

Figure 5. Pentad anomaly frequency below-average thresholds of $5 \mathrm{~mm}, 10 \mathrm{~mm}$, and $15 \mathrm{~mm}$ for the eight pentads in December and January covering the four different maize-growing regions of South Africa

Table 1. The non-parametric Mann-Kendall test of dry pentads using three thresholds for 16 homogeneous rainfall districts for the mid-summer period (1985-2015)

\begin{tabular}{|c|c|c|c|c|c|c|}
\hline \multirow[t]{3}{*}{ District } & \multicolumn{6}{|c|}{ Thresholds } \\
\hline & \multicolumn{2}{|r|}{$>5 \mathrm{~mm}$} & \multicolumn{2}{|r|}{$>10 \mathrm{~mm}$} & \multicolumn{2}{|r|}{$>15 \mathrm{~mm}$} \\
\hline & Z-statistic & Attained significance level & Z-statistic & Attained significance level & Z-statistic & Attained significance level \\
\hline 60 & -1.17 & $76 \%$ & -0.68 & $50 \%$ & -0.65 & $48 \%$ \\
\hline 61 & -0.64 & $48 \%$ & -0.39 & $30 \%$ & -1.73 & $92 \%$ \\
\hline 62 & 0.06 & $5 \%$ & 0.00 & $0 \%$ & 0.91 & $63 \%$ \\
\hline 63 & 0.19 & $15 \%$ & -0.63 & $47 \%$ & -0.53 & $40 \%$ \\
\hline 72 & -1.38 & $83 \%$ & -0.13 & $10 \%$ & -0.50 & $38 \%$ \\
\hline 73 & 0.00 & $0 \%$ & 0.33 & $26 \%$ & 0.35 & $28 \%$ \\
\hline 74 & -0.25 & $19 \%$ & -0.56 & $43 \%$ & -0.64 & $48 \%$ \\
\hline 75 & -0.11 & $9 \%$ & -0.09 & $8 \%$ & -0.15 & $12 \%$ \\
\hline 83 & -1.24 & $79 \%$ & -1.31 & $81 \%$ & -0.75 & $55 \%$ \\
\hline 84 & -0.02 & $1 \%$ & 0.24 & $19 \%$ & -0.43 & $33 \%$ \\
\hline 85 & 1.21 & $77 \%$ & -0.86 & $61 \%$ & -0.13 & $10 \%$ \\
\hline 86 & -1.76 & $92 \%$ & -1.43 & $85 \%$ & -0.57 & $43 \%$ \\
\hline 87 & -0.02 & $2 \%$ & 0.46 & $36 \%$ & 0.24 & $19 \%$ \\
\hline 91 & -1.81 & $93 \%$ & -0.62 & $47 \%$ & -0.50 & $38 \%$ \\
\hline 92 & -0.17 & $13 \%$ & 0.39 & $30 \%$ & 0.53 & $40 \%$ \\
\hline 93 & -1.18 & $76 \%$ & -0.45 & $35 \%$ & -0.67 & $50 \%$ \\
\hline
\end{tabular}

An analysis of total pentad rainfall for 8 pentads in December and January was done to investigate the deviation from the climatological average of the number of dry pentads during the mid-summer period. Anomalies of dry pentad frequency are presented in Fig. 5 using the three thresholds for the period 1985 to 2015. Negative values indicate fewer dry pentads and positive values indicate more dry pentads during the mid-summer period. Anomalies of dry pentad frequency plots for the four districts covering the different maize growing regions of the summer rainfall areas of South Africa are shown in Fig. 5. The non-parametric Mann-Kendall trend test analysis was performed to investigate trends in the frequency of dry spells during the mid-summer period (Hipel and McLeod, 1994; Libiseller and Grimvall, 2002). The trend analysis results for the 16 districts are presented in Table 1 for the dry pentads during the mid-summer using the three thresholds. As presented in Table 1, there is no significant trend in the frequency of dry spells at a $95 \%$ confidence level. However, District 61 showed a decrease in $15 \mathrm{~mm}$ pentad rainfall totals at a $92 \%$ confidence level. Districts 86 and 91 also have shown a decrease in $5 \mathrm{~mm}$ pentad rainfall totals at $92 \%$ and $93 \%$ confidence level, respectively. 
Boxplots of annual frequencies of dry pentads during the midsummer (December-January) using the three thresholds of $5 \mathrm{~mm}$, $10 \mathrm{~mm}$ and $15 \mathrm{~mm}$ are presented in Fig. 6. The bands inside the boxplots show the medians and the ends of the whiskers (vertical lines) represent the minimum and the maximum number of dry pentads. The number of dry pentads was higher for District 87 compared to Districts 74,75 , and 85 , as shown in Fig. 6, indicating more dry pentads for all three thresholds for the 30 -year period.

The Markov chain probability model was used for dry spell analysis using a threshold value of $3 \mathrm{~mm}$ rainfall per day (15 $\mathrm{mm}$ per pentad), as presented in Table 2 . A pentad with less than
$15 \mathrm{~mm}$ rainfall was considered as a dry pentad. The Markov chain model calculates the initial probabilities of getting dry spell $\left(P_{\mathrm{D}}\right)$, conditional probabilities of dry spell followed by dry spell $\left(P_{\mathrm{DD}}\right)$, two (2D) and three (3D) consecutive dry spells. Climatologically, Districts 72, 83 and 93 show a higher likelihood of getting consecutive dry spells than the other regions. Consecutive dry spells also seem more likely to occur during Pentads 73 and 1 . These results are in agreement with the findings of Grobler (1993), who reported mid-summer dry spells for the study area which lasted, on average, 7 to 14 days, occurring typically at the end of December and the beginning of January.

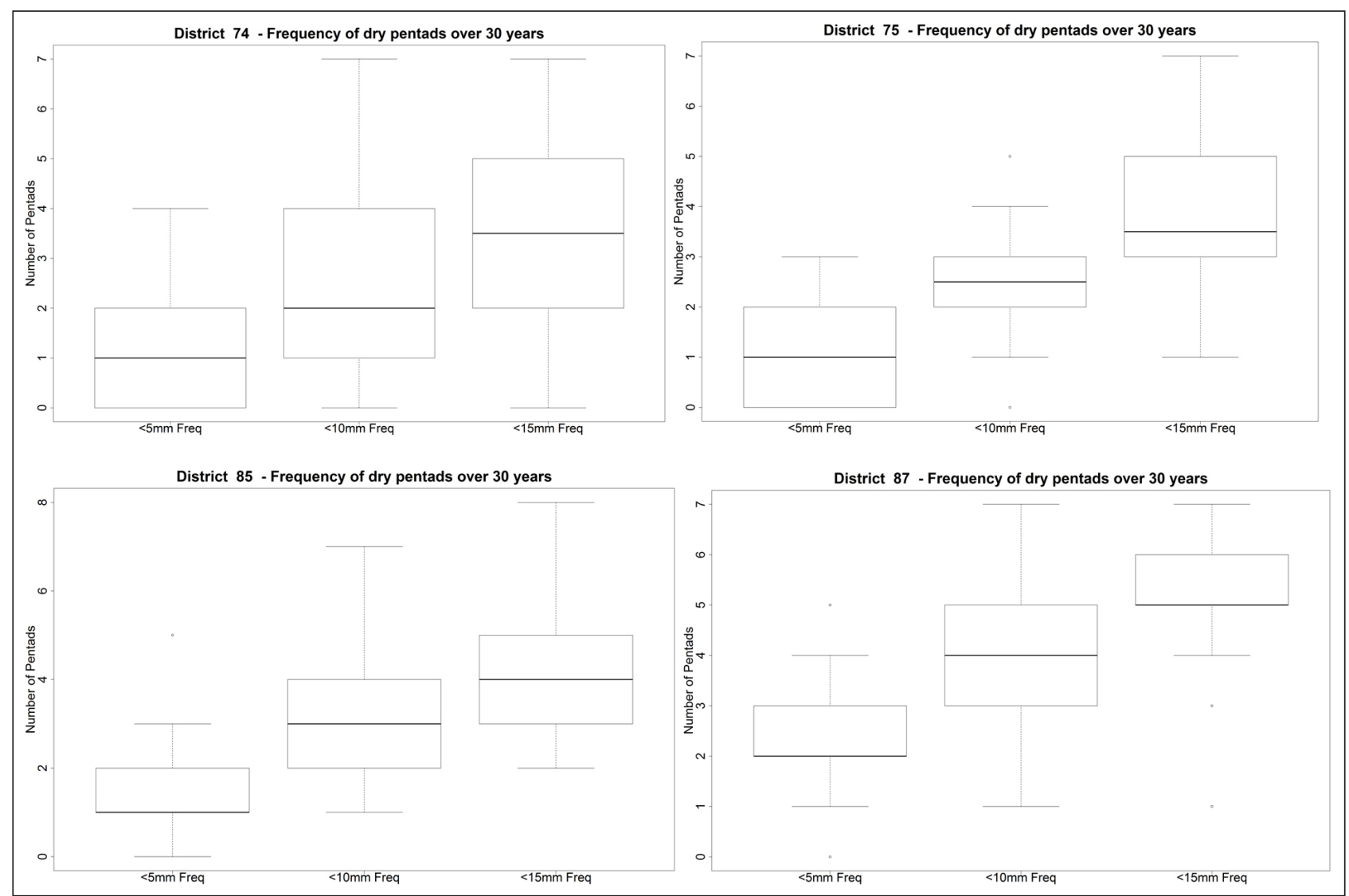

Figure 6. The number of pentads with below-average thresholds of $5 \mathrm{~mm}, 10 \mathrm{~mm}$, and $15 \mathrm{~mm}$ for the eight pentads in December and January (1985-2015) covering the four different maize-growing regions of South Africa

Table 2. Markov chain results for the 16 rainfall districts contained in the study area for the mid-summer period (1985-2015) using a threshold value of $3 \mathrm{~mm}$ rainfall per day (15 $\mathrm{mm}$ per pentad). (A) Probability for a single dry pentad $-P_{\mathrm{D}}$ (B) probability for dry pentad given the previous pentad dry $-P_{\mathrm{DD}}$ (C) probability for two consecutive pentads being dry starting with the pentad $-2 \mathrm{D}$, (D) probability for three consecutive pentads being dry starting with the pentad $-3 D$

\begin{tabular}{|c|c|c|c|c|c|c|c|c|}
\hline \multirow[t]{2}{*}{ District } & \multicolumn{8}{|c|}{ Pentad } \\
\hline & 70 & 71 & 72 & 73 & 1 & 2 & 3 & 4 \\
\hline \multicolumn{9}{|c|}{ (A) $P_{\mathrm{D}}$} \\
\hline 60 & 51.60 & 45.20 & 38.70 & 61.30 & 61.30 & 51.60 & 61.30 & 54.80 \\
\hline 61 & 38.70 & 51.60 & 38.70 & 51.60 & 58.10 & 48.40 & 58.10 & 48.40 \\
\hline 62 & 38.70 & 41.90 & 35.50 & 45.20 & 51.60 & 32.30 & 45.20 & 32.30 \\
\hline 63 & 45.20 & 41.90 & 29.00 & 54.80 & 64.50 & 41.90 & 71.00 & 51.60 \\
\hline 72 & 77.40 & 67.70 & 54.80 & 61.30 & 71.00 & 64.50 & 51.60 & 51.60 \\
\hline 73 & 64.50 & 54.80 & 45.20 & 67.70 & 67.70 & 67.70 & 64.50 & 58.10 \\
\hline 74 & 41.90 & 45.20 & 29.00 & 41.90 & 51.60 & 48.40 & 61.30 & 41.90 \\
\hline 75 & 51.60 & 45.20 & 29.00 & 45.20 & 51.60 & 48.40 & 54.80 & 45.20 \\
\hline 83 & 77.40 & 64.50 & 45.20 & 74.20 & 77.40 & 71.00 & 74.20 & 67.70 \\
\hline 84 & 58.10 & 58.10 & 51.60 & 54.80 & 67.70 & 51.60 & 71.00 & 48.40 \\
\hline 85 & 48.40 & 61.30 & 48.40 & 61.30 & 71.00 & 45.20 & 61.30 & 41.90 \\
\hline 86 & 45.20 & 54.80 & 38.70 & 41.90 & 58.10 & 48.40 & 64.50 & 48.40 \\
\hline 87 & 64.50 & 61.30 & 54.80 & 71.00 & 74.20 & 51.60 & 67.70 & 67.70 \\
\hline 91 & 71.00 & 67.70 & 58.10 & 67.70 & 71.00 & 58.10 & 80.60 & 67.70 \\
\hline 92 & 71.00 & 61.30 & 64.50 & 61.30 & 77.40 & 54.80 & 71.00 & 54.80 \\
\hline 93 & 67.70 & 64.50 & 64.50 & 71.00 & 74.20 & 61.30 & 58.10 & 51.60 \\
\hline
\end{tabular}


Table 2 Continued. Markov chain results for the 16 rainfall districts contained in the study area for the mid-summer period (1985-2015) using a threshold value of $3 \mathrm{~mm}$ rainfall per day (15 mm per pentad). (A) Probability for a single dry pentad $-P_{D}$, (B) probability for dry pentad given the previous pentad dry $-P_{D D}(C)$ probability for two consecutive pentads being dry starting with the pentad - $2 \mathrm{D}$, (D) probability for three consecutive pentads being dry starting with the pentad - 3D

\begin{tabular}{|c|c|c|c|c|c|c|c|c|}
\hline \multirow[t]{2}{*}{ District } & \multicolumn{8}{|c|}{ Pentad } \\
\hline & 70 & 71 & 72 & 73 & 1 & 2 & 3 & 4 \\
\hline \multicolumn{9}{|c|}{ (B) $P_{\mathrm{DD}}$} \\
\hline 60 & 29.00 & 22.60 & 25.80 & 25.80 & 33.30 & 35.50 & 29.00 & 35.50 \\
\hline 61 & 22.58 & 19.35 & 25.81 & 25.81 & 26.67 & 25.81 & 25.81 & 25.81 \\
\hline 62 & 9.70 & 16.10 & 12.90 & 19.40 & 20.00 & 19.40 & 12.90 & 12.90 \\
\hline 63 & 12.90 & 19.40 & 12.90 & 16.10 & 36.70 & 16.10 & 32.30 & 32.30 \\
\hline 72 & 41.90 & 54.80 & 41.90 & 29.00 & 50.00 & 51.60 & 29.00 & 29.00 \\
\hline 73 & 29.00 & 32.30 & 29.00 & 25.80 & 46.70 & 58.10 & 38.70 & 38.70 \\
\hline 74 & 16.10 & 19.40 & 19.40 & 9.70 & 20.00 & 32.30 & 29.00 & 19.40 \\
\hline 75 & 12.90 & 22.60 & 16.10 & 9.70 & 20.00 & 35.50 & 25.80 & 16.10 \\
\hline 83 & 41.90 & 48.40 & 25.80 & 35.50 & 63.30 & 61.30 & 48.40 & 48.40 \\
\hline 84 & 22.60 & 35.50 & 25.80 & 25.80 & 40.00 & 48.40 & 41.90 & 35.50 \\
\hline 85 & 19.40 & 22.60 & 35.50 & 25.80 & 46.70 & 41.90 & 32.30 & 25.80 \\
\hline 86 & 16.10 & 22.60 & 22.60 & 16.10 & 20.00 & 35.50 & 32.30 & 29.00 \\
\hline 87 & 22.60 & 41.90 & 32.30 & 41.90 & 56.70 & 41.90 & 38.70 & 41.90 \\
\hline 91 & 54.80 & 51.60 & 35.50 & 41.90 & 53.30 & 51.60 & 45.20 & 54.80 \\
\hline 92 & 41.90 & 45.20 & 41.90 & 41.90 & 50.00 & 51.60 & 35.50 & 29.00 \\
\hline 93 & 35.50 & 38.70 & 41.90 & 45.20 & 56.70 & 58.10 & 32.30 & 25.80 \\
\hline \multicolumn{9}{|c|}{ (C) $2 \mathrm{D}$} \\
\hline 60 & 11.70 & 11.70 & 10.00 & 20.40 & 21.70 & 15.00 & 21.70 & 14.20 \\
\hline 61 & 7.49 & 13.32 & 9.99 & 13.76 & 14.98 & 12.49 & 14.98 & 10.93 \\
\hline 62 & 6.24 & 5.41 & 6.87 & 9.03 & 9.99 & 4.16 & 5.83 & 4.16 \\
\hline 63 & 8.70 & 5.40 & 4.70 & 20.10 & 10.40 & 13.50 & 22.90 & 15.00 \\
\hline 72 & 42.50 & 28.40 & 15.90 & 30.60 & 36.60 & 18.70 & 15.00 & 15.00 \\
\hline 73 & 20.80 & 15.90 & 11.70 & 31.60 & 39.30 & 26.20 & 25.00 & 13.10 \\
\hline 74 & 8.10 & 8.70 & 2.80 & 8.40 & 16.60 & 14.00 & 11.90 & 4.10 \\
\hline 75 & 11.70 & 7.30 & 2.80 & 9.00 & 18.30 & 12.50 & 8.80 & 8.70 \\
\hline 83 & 37.50 & 16.60 & 16.00 & 47.00 & 47.50 & 34.30 & 35.90 & 30.60 \\
\hline 84 & 20.60 & 15.00 & 13.30 & 21.90 & 32.80 & 21.60 & 25.20 & 12.50 \\
\hline 85 & 10.90 & 21.70 & 12.50 & 28.60 & 29.80 & 14.60 & 15.80 & 8.10 \\
\hline 86 & 10.20 & 12.40 & 6.20 & 8.40 & 20.60 & 15.60 & 18.70 & 6.20 \\
\hline 87 & 27.10 & 19.80 & 23.00 & 40.20 & 31.10 & 20.00 & 28.40 & 37.10 \\
\hline 91 & 36.60 & 24.00 & 24.30 & 36.10 & 36.60 & 26.20 & 44.20 & 24.00 \\
\hline 92 & 32.00 & 25.70 & 27.10 & 30.60 & 40.00 & 19.50 & 20.60 & 14.20 \\
\hline 93 & 26.20 & 27.10 & 29.10 & 40.20 & 43.10 & 19.80 & 15.00 & 21.60 \\
\hline \multicolumn{9}{|c|}{ (D) $3 \mathrm{D}$} \\
\hline 60 & 3.01 & 3.01 & 3.33 & 7.25 & 6.31 & 5.32 & 5.61 & 3.20 \\
\hline 61 & 1.93 & 3.44 & 2.66 & 3.55 & 3.87 & 3.22 & 3.38 & 3.17 \\
\hline 62 & 0.81 & 1.05 & 1.37 & 1.75 & 1.29 & 0.54 & 0.75 & 0.81 \\
\hline 63 & 1.13 & 0.87 & 1.72 & 3.24 & 3.36 & 4.36 & 6.65 & 2.42 \\
\hline 72 & 17.80 & 8.20 & 8.00 & 15.80 & 10.60 & 5.40 & 4.40 & 3.90 \\
\hline 73 & 6.00 & 4.10 & 5.40 & 18.40 & 15.20 & 10.20 & 5.60 & 3.40 \\
\hline 74 & 1.57 & 0.85 & 0.56 & 2.71 & 4.83 & 2.72 & 1.15 & 0.92 \\
\hline 75 & 1.88 & 0.70 & 0.56 & 3.20 & 4.73 & 2.01 & 1.71 & 1.41 \\
\hline 83 & 9.70 & 5.90 & 10.10 & 28.80 & 23.00 & 16.60 & 16.20 & 11.80 \\
\hline 84 & 5.30 & 3.90 & 5.30 & 10.60 & 13.70 & 7.70 & 6.50 & 3.60 \\
\hline 85 & 3.88 & 5.61 & 5.83 & 11.99 & 9.60 & 3.76 & 3.06 & 2.09 \\
\hline 86 & 2.30 & 2.00 & 1.25 & 2.98 & 6.65 & 4.53 & 2.42 & 1.81 \\
\hline 87 & 8.70 & 8.30 & 13.00 & 16.90 & 12.00 & 8.40 & 15.60 & 20.40 \\
\hline 91 & 13.00 & 10.08 & 12.99 & 18.65 & 16.54 & 14.38 & 15.69 & 9.30 \\
\hline 92 & 13.40 & 10.80 & 13.50 & 15.80 & 14.20 & 5.60 & 5.30 & 3.70 \\
\hline 93 & 11.00 & 12.20 & 16.50 & 23.40 & 13.90 & 5.10 & 6.30 & 9.80 \\
\hline
\end{tabular}




\section{Spatial analysis of mid-summer rainfall}

The episode of dry spells (EP) is the number of consecutive dry spells ( $\geq 2$ pentads) in one mid-summer period (mid-December and mid-January) averaged over a 30-year period with less than the threshold value of $15 \mathrm{~mm}$ per pentad. As shown in Fig. 7, the mean EP values varied from 1.69 to 2.10 across the districts. High mean EP values were observed around Districts 75, 86 and 91 in
Mpumalanga, Limpopo and North West Provinces, respectively. Most dry spell episodes with higher EP are concentrated in the north-central part of the study area. Similarly, the standard deviation (STD) of the EP shown in Fig. 8 illustrates that the main deviation from the mean EP is located in District 74. Although high mean values of EP were noticed in the north-central part of the study area there is little variation from the mean EP.

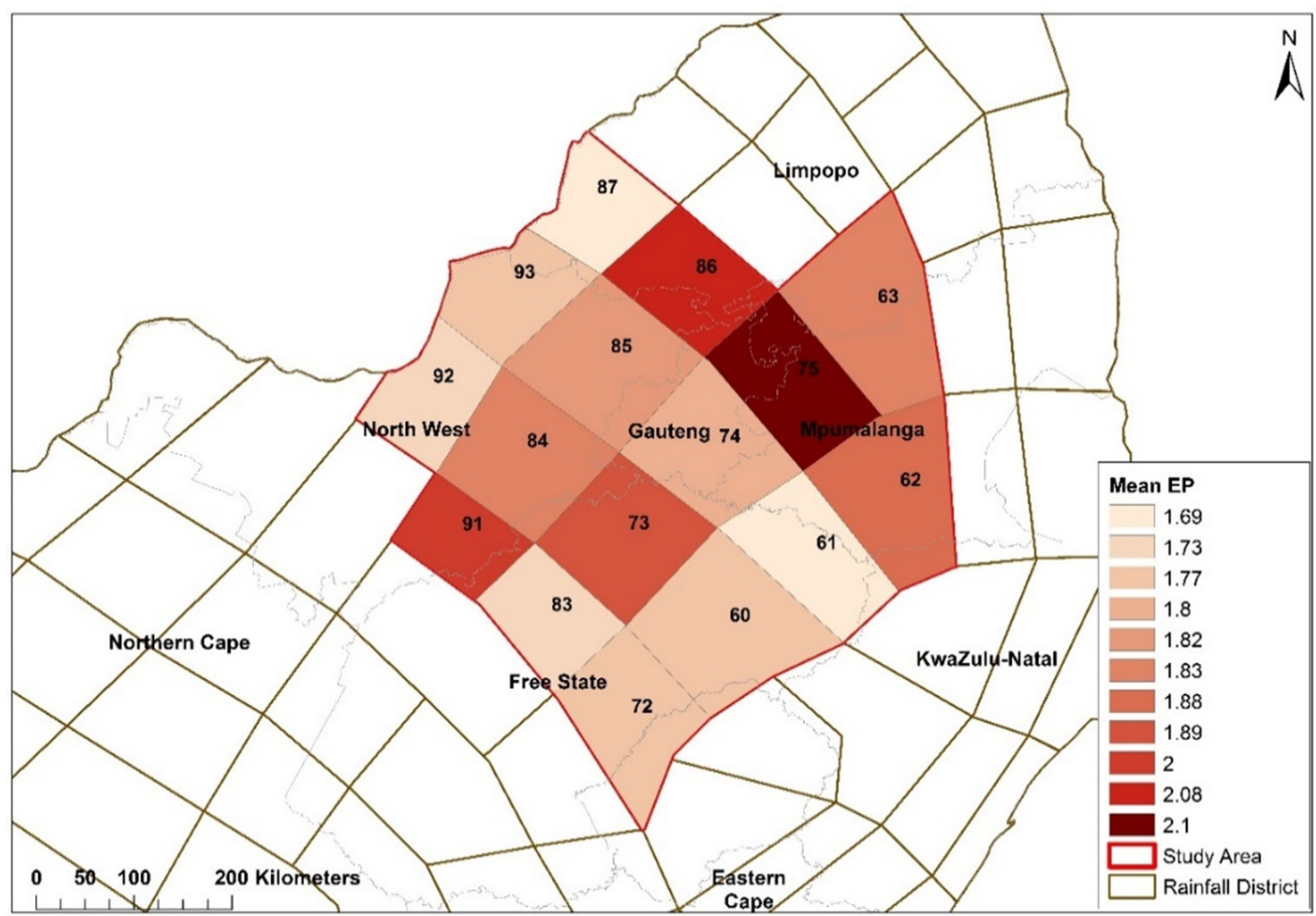

Figure 7. The mean episode of dry spells (EP) during mid-December and mid-January using a threshold value of $15 \mathrm{~mm}$ for the period of 1985-2015. (EP) is the number of consecutive dry spells ( $\geq 2$ pentads) in one mid-summer period

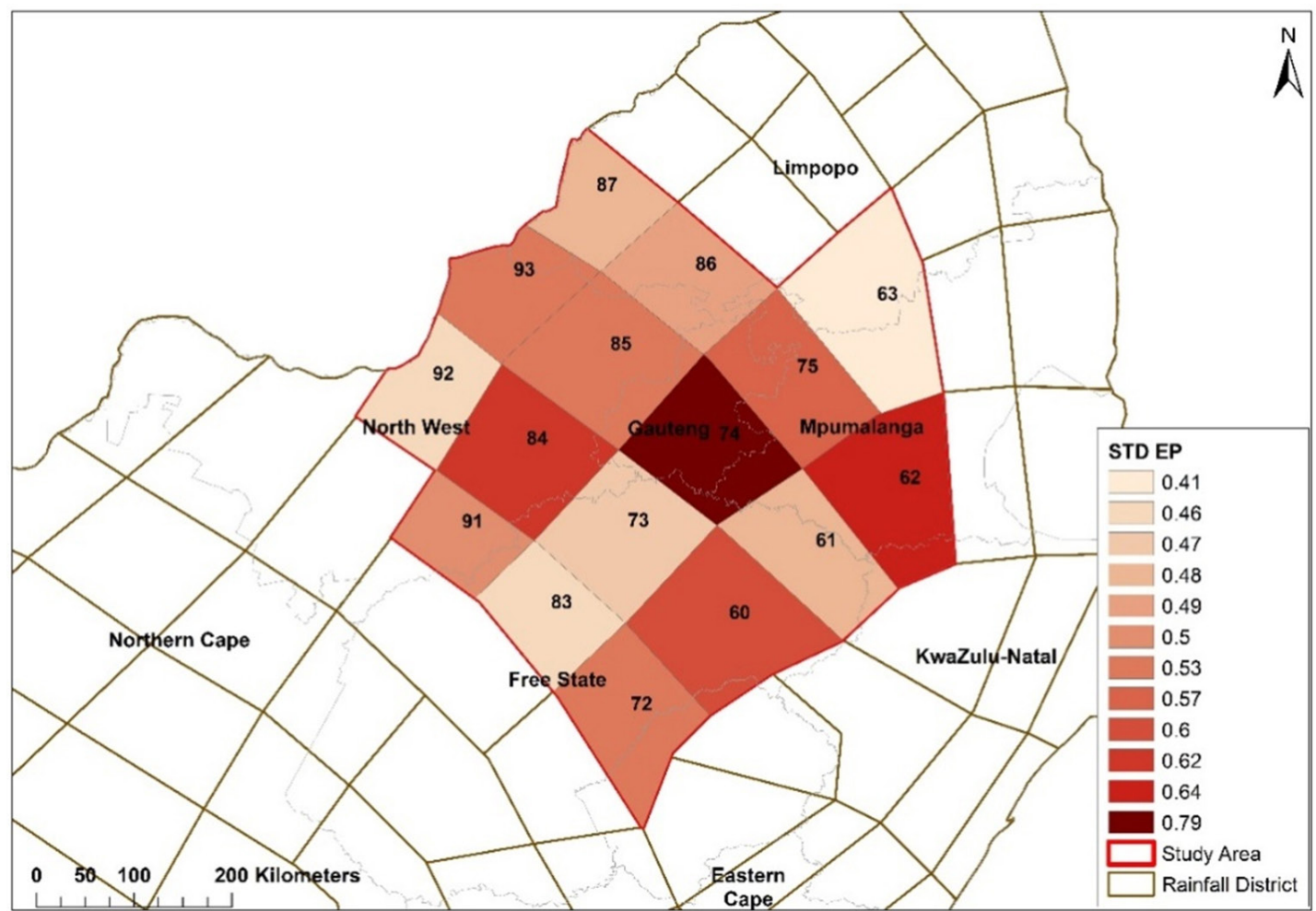

Figure 8. The standard deviation of the episode of dry spells (EP) during mid-December and mid-January using a threshold value of $15 \mathrm{~mm}$ for the period of $1985-2015$ 
The average maximum duration of dry spells (DD), which is the maximum duration of consecutive dry spells using a threshold of $15 \mathrm{~mm}$ between mid-December and mid-January per year, is depicted in Fig. 9 and the deviations from the mean for each district (standard deviation of DD) in Fig. 10. There is a close range of mean DD across the districts; however, there is a decline in the duration of dry spells from the west to east of the study area. As shown in Fig. 9, high mean values of DD are noticeable in Districts 83 and 92 in Free State and North West Provinces, respectively. This indicates that dry pentads are more evident over the districts during the mid-summer period compared to other districts. More deviations from the mean DD were also observed for rainfall Districts 83 and 92 compared to the other districts as shown in Fig. 10.

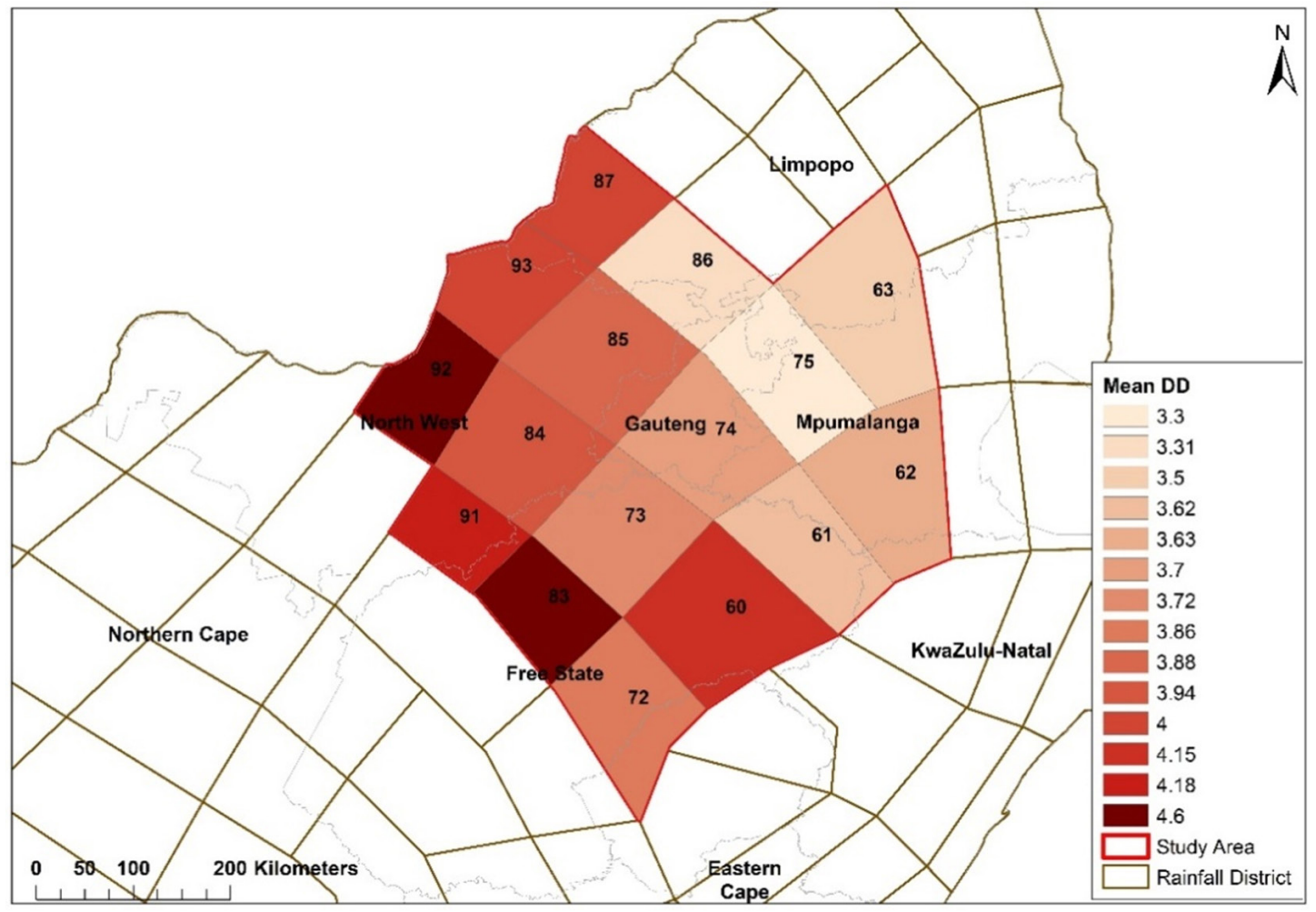

Figure 9. The mean maximum duration of dry pentads (DD) during mid-December and mid-January using a threshold value of $15 \mathrm{~mm}$ for the period of $1985-2015$

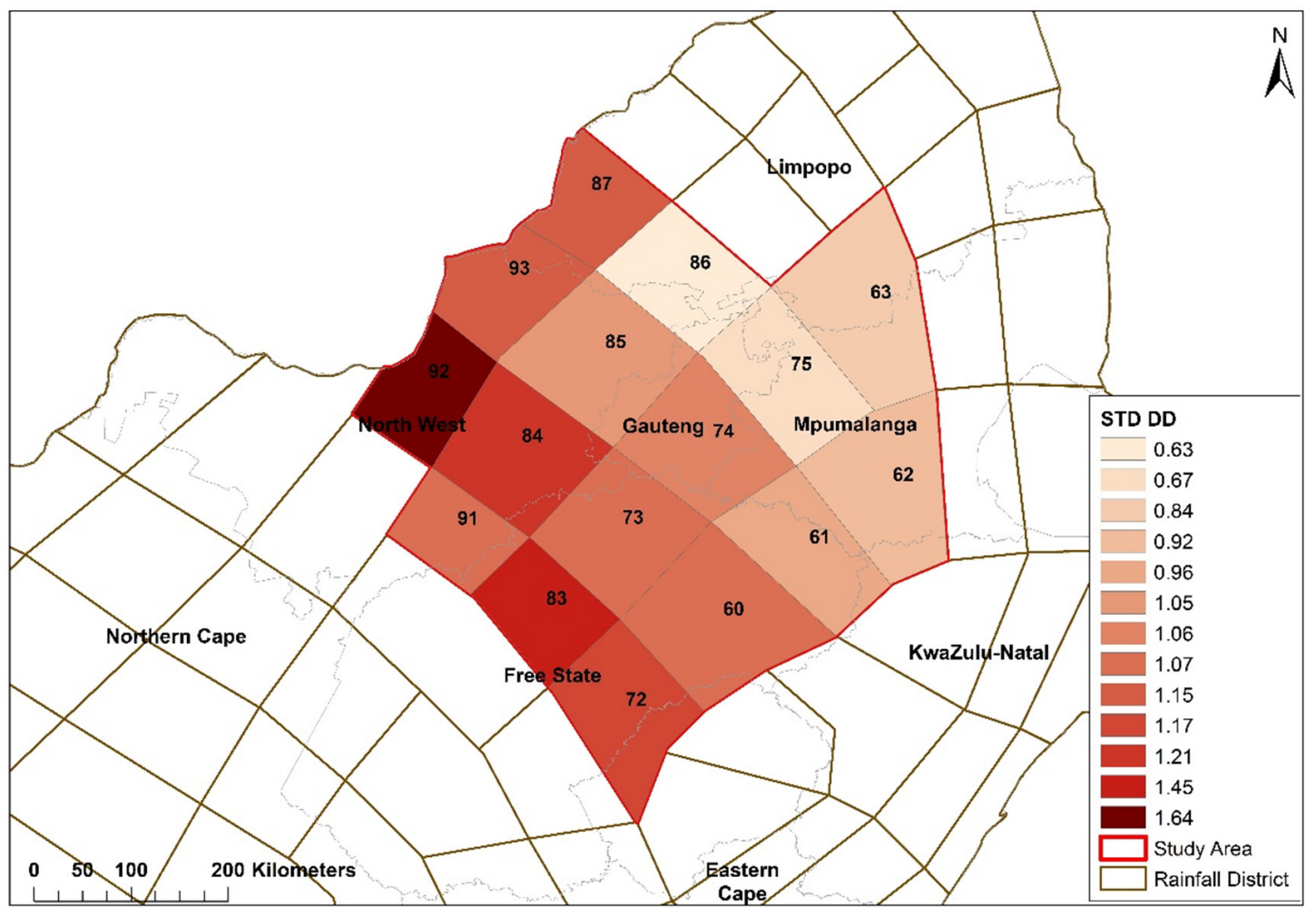

Figure 10. The standard deviation of the maximum duration of dry pentads (DD) during mid-December and mid-January using a threshold value of $15 \mathrm{~mm}$ for the period of $1985-2015$ 


\section{Impacts of dry spells on maize production}

Several studies on rainfall variability in Southern Africa have reported both intra-seasonal and inter-annual variability in summer which is the main cropping season in the region (Landman and Tennant, 2000; Usman and Reason, 2004; Tadross et al., 2005; Mupangwa et al., 2011; Crétat et al., 2011). This observed variability in rainfall and its impact on crop yield makes the Southern Africa region prone to food insecurities. Although the relationships between the total rainfall and crop yield are clear, it is often the variability in seasonal rainfall characteristics such as onset, cessation, and dry spells that is important in terms of adverse effects on agriculture (Tadross et al., 2009).

The maize growing season experiences different rainfall characteristics such as dry spells which may impact phenology and lead to reduced crop yields (Tadross et al., 2009; Moeletsi and Walker, 2012). Maize is mostly planted on drylands in most parts of Southern Africa and is sensitive to water stress (Zinyengere et al., 2014). The yield and quality of maize depend on the distribution of rainfall during the different phenological stages, in addition to other factors (Tadross et al., 2009, Mupangwa et al., 2011). Most studies show that maize plants are more sensitive to water stress during silking and pollination compared to the vegetative stage (Du Plessis, 2003; Masupha et al., 2016).

Several studies have reported on dry and wet spell analysis over southern Africa and their impacts on crop yield (e.g., Usman and Reason 2004; Tadross et al., 2009; Mupangwa et al., 2011; Moeletsi and Walker, 2012; and Duffy and Masere, 2015). However, except for the study by Grobler (1993), little research has been devoted to mid-summer dry spells which usually coincide with the watersensitive growth stages of maize crop. In this study, a detailed spatial and temporal analysis of the mid-summer dry spells was performed for the maize growing areas of the summer rainfall region in South Africa using three thresholds of $5 \mathrm{~mm}, 10 \mathrm{~mm}$, and $15 \mathrm{~mm}$ total rainfall for a pentad. As shown in the previous sections, the frequency (Figs 5 and 6), magnitude (Fig. 7), and duration (Fig. 9) of mid-summer dry spells differ across the rainfall districts in the maize-growing areas of the summer rainfall region in South Africa. These results are in agreement with the findings of Grobler (1993), who reported an increase in length, intensity and occurrence probability of dry spells from east to west of the study area.

Annual frequency of dry pentads for the mid-summer period ranged between 0 and 4 pentads for the $5 \mathrm{~mm}$ threshold and from 1 to 7 for the $10 \mathrm{~mm}$ and $15 \mathrm{~mm}$ thresholds, as presented in Fig. 6. These results are comparable with the study of Usman and Reason (2004), who reported mean frequency of dry spells for the study area ranging between 1 and 7 pentads using a threshold of $5 \mathrm{~mm}$ for the austral summer season (December to February). For meteorological and some hydrological applications, the $5 \mathrm{~mm}$ and $10 \mathrm{~mm}$ thresholds are useful and may suffice; however, for crop production, the $15 \mathrm{~mm}$ ( $3 \mathrm{~mm}$ per day) threshold pentad rainfall is more applicable. Reddy (1990) proposed the use of a $3 \mathrm{~mm}$ threshold per day (15 mm per pentad), which is the minimum rainfall depth threshold value for crops to satisfy their crop water requirement during a growing season. For regions with high evaporative demand, Stern et al. (2003) suggested a higher threshold of $4.95 \mathrm{~mm}$ can be used to define a wet day.

Markov chain results for the 16 rainfall districts contained in the study area for the mid-summer period (1985-2015) show that there is a $32 \%$ to $80 \%$ probability that a single pentad will be dry using the $15 \mathrm{~mm}$ threshold (Table 2). There is a $5 \%$ to $48 \%$ probability of experiencing 2 consecutive dry pentads and, for the same period, there is a $1 \%$ to $29 \%$ probability of getting 3 consecutive dry pentads for the study area, as shown in Table 2.
These results show the probabilities of mid-summer pentads with rainfall less than $15 \mathrm{~mm}$ for the different rainfall districts. During a dry pentad, crops might not be affected if there is enough soil moisture available. However, districts (e.g. 72, 83 and 93) experiencing 2 and 3 consecutive dry pentads are likely to be water-stressed. These dry spells, compounded with the high temperatures experienced during this period, may harm the quality and yield of maize.

Information on dry spell characteristics, such as frequency, duration and intensity, with respect to maize crop phenology is very important for dryland maize production. Studies in parts of the study area in the Limpopo Province by Mzezewa et al. (2010) and Tshililo (2017) have highlighted that dry spells are one of the most important determinants of maize yield reduction if coincident with the water stress-sensitive stages of the maize crop. Therefore, planting dates should be chosen to ensure that this stage coincides with normally favourable growing conditions and does not coincide with mid-summer dry spell periods (Du Plessis, 2003). In-situ rainwater harvesting is a viable option to alleviate water stress in rainfed maize production. Moreover, information on the length of dry spells could be used for selecting drought-tolerant crop varieties and could also be used as a guide for planning supplementary irrigation during the mid-summer dry period.

\section{SUMMARY AND CONCLUSIONS}

Rainfall is one of the most important factors limiting dryland crop production in South Africa. The mid-summer period is particularly significant since a lack of rain for a few days during this period may affect crop yields negatively. Dry spell frequency analyses are used to investigate the effects of sub-seasonal rainfall variability on crop yields since variability in seasonal rainfall totals alone does not show the relationship between rainfall and crop yields. However, little research has been dedicated to dry spell characteristics in South Africa.

In this study, a dry spell was defined as a pentad with a rainfall total that is less than a predefined threshold. Three thresholds of $5 \mathrm{~mm}, 10 \mathrm{~mm}$, and $15 \mathrm{~mm}$ total rainfall for a pentad were used for the analysis of dry spells. This study investigated the spatial and temporal occurrences of the mid-summer dry spells based on magnitude, length and time of occurrence in the summer rainfall region of South Africa. The existence of a climatological dry period within the main rainfall season was investigated using the monthly rainfall totals from October to March. The results show that, climatologically, mid-summer months do not experience lower rainfall than the early and late summer months. However, the dry spell analysis showed that dry pentads occur during midsummer with different intensity, duration and frequency across the maize-growing areas of the summer rainfall region. The nonparametric Mann-Kendall trend analysis for the dry pentads during mid-summer for 16 selected homogeneous rainfall districts indicates that there is no significant trend in the frequency of dry spells at the $95 \%$ significance level. The initial and conditional probabilities of getting a dry spell using the Markov chain model also showed that there is a $32 \%$ to $80 \%$ probability that a single pentad will be dry using the $15 \mathrm{~mm}$ threshold. There is a $5 \%$ to $48 \%$ probability of experiencing 2 consecutive dry pentads and 1 to $29 \%$ probability of getting 3 consecutive dry pentads. Consecutive dry spells mostly seem to occur during Pentads 73 (end of December) and 1 (beginning of January). Furthermore, the Markov chain analysis showed a decrease in the probability of dry spells from west to east of the study area. Analysis of the duration and intensity of dry spells also showed a decrease from west to east of the study area.

The research presented in this study will significantly contribute to dry spell research in South Africa and addresses some of the 
research gaps in dry spell analysis studies, which are of utmost importance for rainfed crop production. The findings from this study will assist farmers and decision-makers to adjust planting dates of summer crops to ensure favourable growing conditions during the water stress-sensitive growth stages. Information about dry spells could also be used for selecting a crop variety in a given location and for planning supplementary irrigation.

\section{ACKNOWLEDGMENTS}

The research presented in this paper forms part of Water Research Commission (WRC) Project No. K5/2830 'An investigation of the historical and projected occurrence of the South African mid-summer drought and its implications for the agro-water budget.' Funding from the WRC and the South African Weather Service (SAWS) for this study is gratefully acknowledged. The contributions of the members of the WRC Reference Group for Project No. K5/2830 are also gratefully acknowledged.

\section{REFERENCES}

AgWeb (2015) South Africa major and minor corn growing areas AgWeb/NOAA/USDA. URL: https://www.agweb.com/article/southafrica-corn-crop-seen-shrinking-further-as-drought-spreads-blmg (Accessed 6 September 2019).

BÄRRING L, HOLT T, LINDERSON ML, RADZIEJEWSKI M, MORIONDO M and PALUTIKOF JP (2006) Defining dry/wet spells for point observations, observed area averages, and regional climate model grid-boxes in Europe. Clim. Res. 31 (1) 35-49. https://doi. org/10.3354/cr031035

BHALOTRA YPR (1984) Climate of Botswana, Part I. Climatic controls. Department of Meteorological services, Ministry of Transport and Communications, Botswana.

CEBALLOS A, MARTINEZ-FERNANDEZ J and LUENGO-UGIDOS MA (2004) Analysis of rainfall trends and dry period on a pluviometric gradient representative of Mediterranean climate in the Duero Basin, Spain. J. Arid Environ. 58 214-232. https://doi. org/10.1016/j.jaridenv.2003.07.002

CRÉTAT J, MACRON C, POHL B and RICHARD Y (2011) Quantifying internal variability in a regional climate model: a case study for Southern Africa. Clim. Dyn. 37 1335-1356. https://doi.org/10.1007/ s00382-011-1021-5

DOUGUEDROIT A (1987) The variation of dry spells in Marseilles from 1865 and 1984. J. Climatol. 7 541-551. https://doi.org/10.1002/ joc. 3370070603

DUFFY KJ and MASERE TP (2015) Effect of within-season daily rainfall distribution on maize crop yields. Outlook Agr. 44 267-271. https://doi.org/10.5367/oa.2015.0223

DU PLESSIS J (2003) Maize production. Directorate Agricultural Information Services, Department of Agriculture in cooperation with ARC-Grain Crops Institute. Potchefstroom, South Africa.

ENGELBRECHT CJ, LANDMAN WA, ENGELBRECHT FA and MALHERBE J (2014) A synoptic decomposition of rainfall over the Cape south coast of South Africa. Clim. Dyn. 44 2589-2607. https:// doi.org/10.1007/s00382-014-2230-5

FREI C, CHRISTENSEN JH, DE'QUE' M, JACOB D, JONES RG and VIDALE PL (2003) Daily precipitation statistics in regional climate models: evaluation and intercomparison for the European Alps. $J$ Geophys. Res. 108 (D3) 4124. https://doi.org/10.1029/2002JD002287

GROBLER EJML (1993) Die midsomerdroogte in the sentrale dele van die somerreenvalgebied van Suid Afrika. MSc. thesis, University of Stellenbosch.

HARRISON MSJ (1984) A generalized classification of South African summer rain-bearing synoptic systems. J. Climatol. 4 (5) $547-$ 560. https://doi.org/10.1002/joc.3370040510

HART NCG, REASON CJC and FAUCHEREAU N (2010) Tropicalextratropical interactions over southern africa: three cases of heavy summer season rainfall. Mon. Weather Rev. 138 (7) 2608-2623. https://doi.org/10.1175/2010MWR3070.1

HIPEL KW and MCLEOD AI (1994) Time Series Modelling of Water Resources and Environmental Systems. Elsevier Science, Amsterdam. 1014 pp.
KARNAUSKAS KB, SEAGER R, GIANNINI A and BUSALACCHI AJ (2013) A simple mechanism for the climatological midsummer drought along the Pacific coast of Central America. Atmosfera. 26 (2) 261-281. https://doi.org/10.1016/S0187-6236(13)71075-0

KRUGER AC (2011) Identification and quality control procedures for rainfall stations: 1961-2010. South African Weather Service Report, CLS-RES-REP-2011-10.1. South African Weather Service, Pretoria.

KRUGER AC and NXUMALO MP (2017) Historical rainfall trends in South Africa: 1921-2015. Water SA. 43 (2) 285-297. http://dx.doi. org/10.4314/wsa.v43i2.12

LANDMAN WA and TENNANT W J (2000) Statistical downscaling of monthly forecasts. Int. J. Climatol. 20 1521-1532. https://doi. org/10.1002/1097-0088(20001115)20:13<1521::AID-JOC558>3.0.CO; 2-N

LIBISELLER C and GRIMVALL A (2002) Performance of partial Mann-Kendall tests for trend detection in the presence of covariates. Environmetrics. 13 71-84. https://doi.org/10.1002/env.507

MARTIN-VIDE J and GOMEZ L (1999) Regionalization of peninsular Spanish based on the length of dry spells. Int. J. Climatol. 19 (5) 537-555. https://doi.org/10.1002/(SICI)1097-0088(199904)19: 5<537::AID-JOC371>3.0.CO;2-X

MASUPHA TE, MOELETSI ME and TSUBO M (2016). Dry spells assessment with reference to the maize crop in the Luvuvhu River catchment of South Africa. Phys. Chem. Earth. 92 99-111. https:// doi.org/10.1016/j.pce.2015.10.014

MOELETSI ME and WALKER S (2012) Rainy season characteristics of the Free State Province of South Africa with reference to rain-fed maize production. Water SA. 38 (5) 775-782. https://doi.org/10.4314/ wsa.v38i5.17

MOON SE, RYOO SB and KWON JG (1994) A Markov chain model for daily precipitation occurrence in South Korea. Int. J. Climatol. 14 1009-1016. https://doi.org/10.1002/joc.3370140906

MUPANGWA W, WALKER S and TWOMLOW S (2011) Start, end and dry spells of the growing season in semi-arid southern Zimbabwe. J. Arid Environ. 75 1097-1104. https://doi.org/10.1016/j. jaridenv.2011.05.011

MZEZEWA J, MISI T and VAN RENSBURG L (2010) Characterisation of rainfall at a semi-arid ecotope in the Limpopo Province (South Africa) and its implications for sustainable crop production. Water SA. 36 (1) 19-26. https://doi.org/10.4314/wsa.v36i1.50903

NCAR (2018) National Center for Atmospheric Research Staff (eds). The climate data guide: cpc unified gauge-based analysis of global daily precipitation. URL: https://climatedataguide.ucar.edu/climatedata/cpc-unified-gauge-based-analysis-global-daily-precipitation (Accessed 21 July 2019).

NGETICH KF, MUCHERU-MUNA M, MUGWE JN, SHISANYA CA, DIELS J and MUGENDI DN (2014) Length of growing season, rainfall temporal distribution, onset and 61 cessation dates in the Kenyan highlands. Agric. For. Meteorol. 188 24-32. https://doi. org/10.1016/j.agrformet.2013.12.011

PERDIGON-MORALES J, ROMERO-CENTENO R, PEREZ PO and BARRET BS (2017) The midsummer drought in Mexico: perspectives on duration and intensity from the CHIRPS precipitation database. Int. J. Climatol. 38 (5) 2174-2186. https://doi.org/10.1002/joc.5322

PEREIRA LS, CORDERY I and IACOVIDES I (2009) Coping with water scarcity. In addressing the challenges; Springer Science and Business Media: Dordrecht, The Netherlands. 382pp.

PERZYNA G (1994) Spatial and temporal characteristics of maximum dry spells in southern Norway. Int. J. Climatol. 14 895-909. https:// doi.org/10.1002/joc.3370140806

REASON CJC, ROUAULT M, MELICE JL and JAGADHEESHA D (2002) Interannual winter rainfall variability in SW South Africa and large scale ocean-atmosphere interactions. Meteorol. Atmos. Phys. 80 19-29. https://doi.org/10.1007/s007030200011

REDDY SJ (1990) Methodology: Agro-climatic analogue technique and applications as relevant to dry land agriculture. Agro climatology Series Eth 86/21-WMO/UNDP, NMSA 60 pp.

RICHARD Y, FAUCHEREAU N, POCCARD I, ROUAULT $M$ and TRZASKA S (2001) $20^{\text {th }}$ century droughts in Southern Africa spatial and temporal variability, teleconnections with oceanic and atmospheric conditions. Int. J. Climatol. 21 873-895. https://doi. org/10.1002/joc. 656 
SAWB (South African Weather Bureau) (1972) WB35. Climate of South Africa. Part 10. District rainfall for South Africa and the annual march of rainfall over Southern Africa. South African Weather Bureau, Pretoria.

STERN R, KNOCK J, RIJKS D and DALE I (2003) INSTAT Climatic Guide. 398 pp. http://www.reading.ac.uk/ssc/software/instat/clim atic.pdf (Accessed 9 July 2020).

TADROSS MA, HEWITSON BC and USMAN MT (2005) The interannual variability on the onset of the maize growing season over South Africa and Zimbabwe. J. Clim. 18 3356-3372. https://doi. org/10.1175/JCLI3423.1

TADROSS M, SUAREZ P, LOTSCH A, HACHIGONTA S, MDOKA M, UNGANAI L, LUCIO F, KAMDONYO D and MUCHINDA M (2009) Growing-season rainfall and scenarios of future change in southeast Africa: Implications for cultivating maize. Clim. Res. 40 147-161. https://doi.org/10.3354/cr00821

TALJAARD JJ (1986) Change of rainfall distribution and circulation patterns over Southern Africa in summer. J. Climatol. 6 579-592. https://doi.org/10.1002/joc.3370060602
TALJAARD JJ (1996) Atmospheric circulation systems, synoptic climatology and weather phenomena of South Africa: Part 6: Rainfall in South Africa. Technical Paper 32. South African Weather Bureau, Pretoria.

TSHILILO FP (2017) Rainy season characteristics with reference to maize production for the Luvuvhu river catchment, Limpopo Province, South Africa. PhD thesis, University of KwaZulu-Natal.

USMAN MT and REASON CJC (2004). Dry spell frequencies and their variability over southern Africa. Clim. Res. 26 199-211. https://doi. $\operatorname{org} / 10.3354 / \mathrm{cr} 026199$

ZINYENGERE N, CRESPO O, HACHIGONTA S and TADROSS M (2014) Local impacts of climate change and agronomic practices on dry land crops in Southern Africa. Agr. Ecosyst. Environ. 197 1-10. https://doi.org/10.1016/j.agee.2014.07.002 